\title{
The relation between chronic neck pain and hypertension (Ashatra city study)
}

Keyword: chronic neck pain, cervical spondylosis, risk factors, hypertension

\section{Background}

An idea raised in our field of work a few years ago claim that chronic neck pain and cervical spondylosis were a causative factors of hypertension, and as hypertension and cervical spondylosis are common in middle age and old people it may be a true story or it just a coincidence.

\section{Hypertension}

Hypertension by itself is one of a common disease for increase the mortality in associated to cardiovascular diseases in both developing and developed countries. ${ }^{1}$ So It's important to get attention about the hypertension causes and risks factors, and focusing on a disorder as it can be caused by multiple environmental and inherited risks factors. ${ }^{2,3}$ The prevalence of high blood pressure in adult are ranged from 30 $-45 \%$, in $2015 .{ }^{4}$ This high rate is across the world, and are irrespective to income status, so it can be found in the low, mid, and high income countries. Hypertension more common with aging, as prevalence of more than $60 \%$ in people how aged more than 60 years because that the populations age, become more sedentary lifestyles, and increase their body weight, so the prevalence of hypertension will continue to be rise. ${ }^{5}$

\section{Risk factors for raised blood pressure}

a) High salt intake (adding salt on cooked meal more risky than during cocking).

b) Low potassium intake (low fruit and vegetable consumption).

c) Increase body weight (sedentary lifestyle, rise the incidence of joint osteoarthritis).

d) No or lack of physical exercise.

e) Excess consumption of alcohol.,7

\section{Cervical spondylosis}

Cervical Spondylosis and chronic neck pain one of a common disorders of the spine, caused by the degeneration of cervical intervertebral discs and facet joints. These structures support and transmit the forces between vertebrae, With time degeneration process progress and the bony spur (osteophytic) will develop which may narrowing the spine canal diameter, ${ }^{8}$ and so increase the pressure on the spinal cord lead to neurological and vascular changes. Spondylosis considered as age related degenerative changes in the spinal column structures, and radiographic findings of cervical spondylosis are frequently notice in asymptomatic adults. ${ }^{9}$ Variable degree of disc degeneration found in people about $25 \%$ of people younger than 40 years of age, half of people over 40 years of age, and $85 \%$ of individuals over 60 years of age. ${ }^{10}$ The radiculopathy and/or myelopathy may result in a significant disability. ${ }^{11}$ Pain that arising from upper cervical region may be referred to the head, and the patient
Volume II Issue 2 - 2019

\author{
Nibras Salim,' Soad Salman, ${ }^{2}$ Abbas \\ Alhabeeb ${ }^{3}$ \\ 'Orthopedics, Alkarama Teaching Hospital, Iraq \\ ${ }^{2}$ Dermatology, Alkarama Teaching Hospital, Iraq \\ ${ }^{3}$ Rheumatology, Alkarama Teaching Hospital, Iraq
}

Correspondence: Nibras Salim, Orthopedics, Alkarama Teaching Hospital, Iraq, Tel 0096477। I636I65,

Email nibrassalim.ns@gmail.com

Received: February 26, 2019 | Published: March 12, 2019

how unaware of had any cervical problem, the headache will be the presenting feature. ${ }^{12}$

\section{Causes of chronic neck pain}

i. Non specific neck pain: Most patients who present with neck pain have non-specific (simple), postural basis.

ii. Mechanical: disc prolapse or diffuse idiopathic skeletal hyperostosis.

iii. Inflammatory disease: rheumatoid arthritis, ankylosing spondylitis.

iv. Metabolic diseases: Paget's, osteoporosis, gout, or pseudogout.

v. Infections: bacterial osteomyelitis or tuberculosis.

vi. Malignancy: primary tumors, secondary deposits, or myeloma. ${ }^{13}$

The neck pain is either to be acute or chronic lasting more than 12 weeks and with or without an identifiable precipitating events, ${ }^{14}$ may lead to incapacities and working productivity losses. ${ }^{15}$ Hypertension (HT) and cervical spondylosis are common disorder being increasingly observed in the population. ${ }^{4,5,16}$

\section{Pathophysiology}

The perception of acute pain plays an important role in the preventing of tissue damage. The ascending of recruitment of segmental spinal reflexes through the physiological neuronal connections activated the sympathetic nervous system, which increases peripheral resistances, heart rate, and stroke volume. The response also involves the neuroendocrine system, and, in particular, the hypothalamic-pituitary-adrenal axis, in addition to further activation of the sympathetic system by adrenal glands. However, in proportion to an elevation in resting blood pressure, there is a contemporary and progressive reduction in sensitivity to acute pain, which could result in a tendency to restore arousal levels in the presence of painful stimuli. The pathophysiological pattern is significantly different in the setting of chronic pain, in which the adaptive relationship between blood pressure and pain sensitivity is substantially reversed. ${ }^{17}$ In healthy individuals, elevated blood pressure is associated with 
diminished acute pain sensitivity to acute pain. These cardiovascular/ pain regulatory system interactions appear altered in patients with chronic pain; elevated blood pressure is associated with increased acute and chronic pain responsiveness. If these alterations reflect failure of overlapping systems modulating pain and blood pressure, it was expected that prevalence of clinical hypertension would be increased in the chronic pain population. ${ }^{18,19}$

\section{Patients and methods}

Hypertension and chronic neck pain are highly prevalent in adult populations. The objective of this study was to investigate the association between hypertension and chronic neck pain. We included all age groups, both sex, any income level, all education level, all occupation, body mass index (BMI), smoking status, alcohol consumption, and moderately exerting physical activity were included as general, socioeconomic, and lifestyle-related characteristics. We studied 3543 patients, 2588 of them were females and 955 males in ratio 2.7:1, in ASHATRA general hospital in the south of Iraq (ASHATRA study), from the first of January 2015 to the first of January 2019 , the patients attended to the hospital and to the privet clinics with chronic neck pain (more than 12 weeks).
Clinical assessment of all patients was done for the diagnosis the cervical spondylosis causes of their pain by thorough clinical examinations and radiological examinations to exclude any predisposing factors and underlying causes, all of the patients that selected fall in the same categories of body weight, life style, race, no previous trauma or any underlying causes of neck pain like infection and tumor. Blood pressure was measured by trained doctors and nurses using a mercury sphygmomanometer with $25-35 \mathrm{~cm}$ cuff in a sitting position with arm supported at heart level after a 5 minute rest. Measurements were recorded to the closest $2 \mathrm{mmHg}$ on the manometer, we exclude the patients with first degree relative that had HT and those with diabetes mellitus DM.

In 2015 from the first of Jan. To the 31 of Dec. there were 978 patients in total complain from chronic neck pain as 726 females and 252 males (Table 1). The total no. of patients with chronic neck pain in 2016 were 932 in total as 665 females and 267 males (Table 2). The total No. of patients had chronic neck pain in 2017 were 725 in total as 523 females and 202 males in 2.5:1 ratio (Table 3). The total No. of patients that suffer from chronic neck pain in 2018 were 908 and the female patients were 674 and males were234 in 2.8: 1 ratio (Table 4).

Table I Number of chronic neck pain of females and males patients in 2015

\begin{tabular}{|c|c|c|c|c|c|c|c|c|c|c|c|c|c|c|}
\hline \multirow{2}{*}{ Months } & \multicolumn{2}{|c|}{$<20$ years } & \multicolumn{2}{|c|}{$20-30 y$} & \multicolumn{2}{|c|}{$30-40 y$} & \multicolumn{2}{|c|}{$40-50 y$} & \multicolumn{2}{|c|}{$50-60 y$} & \multicolumn{2}{|c|}{$>60 y$} & \multicolumn{2}{|c|}{ Total } \\
\hline & $\mathrm{F}$. & M. & $\mathrm{F}$. & M. & $\mathrm{F}$. & M. & $\mathrm{F}$. & M. & $\mathrm{F}$. & M. & $\mathrm{F}$ & M. & $\mathrm{F}$. & M. \\
\hline Jan & 3 & 0 & 13 & 2 & 19 & 4 & 21 & 5 & 7 & 3 & 5 & 4 & 68 & 18 \\
\hline Feb & 2 & 0 & 7 & 6 & 15 & 6 & 17 & 3 & 10 & 3 & 10 & I & 61 & 19 \\
\hline Mar & 2 & 0 & 16 & 7 & 14 & 9 & 15 & 6 & 16 & 4 & 5 & I & 68 & 27 \\
\hline Apr & 2 & I & 13 & 3 & 17 & 8 & 13 & 8 & 12 & 4 & 4 & 2 & 61 & 26 \\
\hline May & I & 0 & 16 & 4 & 15 & 9 & 15 & 6 & 6 & 5 & 8 & 0 & 61 & 24 \\
\hline Jun & 1 & I & 14 & 4 & 11 & 4 & 14 & 5 & 10 & 5 & 10 & 0 & 60 & 19 \\
\hline Jul & 2 & 0 & 7 & 2 & II & 4 & 8 & 5 & 6 & 3 & 3 & 4 & 37 & 18 \\
\hline Aug & I & I & 15 & 4 & 15 & 6 & 11 & 2 & 15 & 5 & 9 & 3 & 66 & 21 \\
\hline Sep & 2 & 2 & 16 & 6 & 17 & 4 & 19 & 7 & 10 & 2 & II & 10 & 75 & 31 \\
\hline Oct & 5 & I & 13 & I & 18 & 7 & 10 & 10 & 9 & 4 & 5 & I & 60 & 24 \\
\hline Nov & 3 & 0 & 16 & 2 & 20 & 5 & 16 & 4 & 6 & 3 & 7 & 0 & 68 & 14 \\
\hline Dec & 3 & 2 & II & I & 10 & 3 & 2 & 3 & 8 & 1 & 7 & 1 & $4 I$ & II \\
\hline Total & 27 & 8 & 157 & 42 & 182 & 69 & 161 & 64 & 115 & 42 & 84 & 27 & 726 & 252 \\
\hline
\end{tabular}

F, female; $M$, male

Table 2 The chronic neck pain of female and male patients in 2016

\begin{tabular}{|c|c|c|c|c|c|c|c|c|c|c|c|c|c|c|}
\hline \multirow{2}{*}{ Months } & \multicolumn{2}{|c|}{$<20 y$} & \multicolumn{2}{|c|}{$20-30 y$} & \multicolumn{2}{|c|}{$30-40$ y } & \multicolumn{2}{|c|}{$40-50$ y } & \multicolumn{2}{|c|}{$50-60$ y } & \multicolumn{2}{|c|}{$>60 y$} & \multicolumn{2}{|c|}{ Total } \\
\hline & $\mathrm{F}$. & M. & F. & M. & F. & M. & F. & M. & F. & M. & F. & M. & $\mathrm{F}$. & M. \\
\hline Jan & 5 & 2 & 13 & 4 & 17 & 6 & 24 & 2 & 10 & 7 & II & 5 & 80 & 26 \\
\hline Feb & 2 & 2 & 15 & 3 & 14 & 2 & 16 & 3 & 8 & 3 & 10 & 4 & 65 & 17 \\
\hline Mar & 1 & 2 & 7 & 5 & 15 & 9 & 18 & 7 & 14 & 3 & 9 & 2 & 64 & 28 \\
\hline Apr & 1 & 0 & 12 & I & 17 & 6 & 12 & 5 & 10 & 4 & 8 & 7 & 60 & 23 \\
\hline May & 3 & 0 & 6 & 4 & 5 & 5 & 7 & 4 & 7 & 2 & 6 & 2 & 34 & 17 \\
\hline Jun & 2 & I & 15 & 4 & 19 & 5 & 13 & 3 & 6 & 1 & 7 & 3 & 62 & 17 \\
\hline Jul & 0 & 0 & 3 & 7 & 7 & 8 & 13 & 8 & 8 & 3 & 9 & 2 & 40 & 28 \\
\hline Aug & 2 & 0 & 15 & 5 & 10 & II & II & 5 & 5 & 3 & 6 & 2 & 49 & 26 \\
\hline Sep & 3 & 0 & 8 & I & 12 & 10 & 15 & 9 & II & 4 & II & 2 & 60 & 26 \\
\hline
\end{tabular}


Table Continued....

\begin{tabular}{|c|c|c|c|c|c|c|c|c|c|c|c|c|c|c|}
\hline \multirow{2}{*}{ Months } & \multicolumn{2}{|c|}{$<20 y$} & \multicolumn{2}{|c|}{$20-30 y$} & \multicolumn{2}{|c|}{$30-40 y$} & \multicolumn{2}{|c|}{$40-50 y$} & \multicolumn{2}{|c|}{$50-60$ y } & \multicolumn{2}{|c|}{$>60 y$} & \multicolumn{2}{|c|}{ Total } \\
\hline & $\mathrm{F}$ & M. & $\mathrm{F}$. & M. & F. & M. & F. & M. & F. & M. & $\mathrm{F}$. & M. & & M. \\
\hline Oct & I & 3 & 9 & 3 & 10 & 5 & 10 & 8 & 4 & 2 & 13 & 3 & 47 & 24 \\
\hline Nov & 3 & I & 8 & 4 & 18 & 4 & 10 & 5 & 10 & 4 & 6 & 4 & 55 & 22 \\
\hline Dec & I & 0 & 15 & 2 & 10 & 4 & 10 & 2 & 4 & 2 & 9 & 3 & 49 & 13 \\
\hline Total & 24 & II & 126 & 43 & 154 & 75 & 159 & 61 & 97 & 38 & 105 & 39 & 665 & 267 \\
\hline
\end{tabular}

Table 3 No. of females and male patients with chronic neck pain in 2017

\begin{tabular}{|c|c|c|c|c|c|c|c|c|c|c|c|c|c|c|}
\hline \multirow{2}{*}{ Months } & \multicolumn{2}{|c|}{$<20 y$} & \multicolumn{2}{|c|}{$20-30 y$} & \multicolumn{2}{|c|}{$30-40 y$} & \multicolumn{2}{|c|}{$40-50 y$} & \multicolumn{2}{|c|}{$50-60 y$} & \multicolumn{2}{|c|}{$>60 y$} & \multicolumn{2}{|c|}{ Total } \\
\hline & F. & M. & F. & M. & F. & M. & F. & M. & F. & M. & F. & M. & $\mathrm{F}$. & M. \\
\hline Jan & 0 & 0 & 10 & I & II & 3 & 15 & 8 & 7 & 2 & 10 & 2 & 53 & 16 \\
\hline Feb & 0 & I & 9 & 0 & 6 & 5 & 12 & 4 & 6 & 0 & 4 & 2 & 37 & 12 \\
\hline Mar & 2 & 0 & II & 3 & 15 & 5 & 16 & 7 & 6 & 4 & 7 & 8 & 57 & 27 \\
\hline Apr & I & I & 13 & I & 14 & 5 & 12 & 8 & 4 & 3 & 6 & 2 & 50 & 20 \\
\hline May & 0 & 0 & 5 & 2 & 9 & 4 & 8 & I & 7 & I & 6 & I & 35 & 9 \\
\hline Jun & 2 & 0 & 5 & 7 & 6 & 4 & 6 & 3 & 5 & I & 3 & 7 & 27 & 22 \\
\hline Jul & I & 0 & 13 & 2 & II & 4 & 13 & 3 & 10 & 0 & II & I & 59 & 10 \\
\hline Aug & 2 & 2 & 10 & 3 & 10 & 7 & 12 & 4 & 8 & I & 5 & 2 & 47 & 19 \\
\hline Sep & I & 0 & II & 3 & 12 & 6 & 10 & 7 & 6 & I & 10 & 2 & 50 & 19 \\
\hline Oct & I & I & 9 & 2 & 9 & 7 & 8 & 4 & 9 & 2 & 4 & I & 40 & 17 \\
\hline Nov & 2 & 0 & 3 & 0 & 5 & 2 & 7 & 2 & 5 & 3 & 9 & 3 & 31 & 10 \\
\hline Dec & 0 & 0 & 7 & 0 & 10 & 5 & 9 & 8 & 7 & I & 4 & 7 & 37 & 21 \\
\hline Total & 12 & 5 & 106 & 24 & 118 & 57 & 128 & 59 & 80 & 19 & 79 & 38 & 523 & 202 \\
\hline
\end{tabular}

Table 4 No. of females and males with chronic neck pain in 2018

\begin{tabular}{|c|c|c|c|c|c|c|c|c|c|c|c|c|c|c|}
\hline \multirow{2}{*}{ Months } & \multicolumn{2}{|c|}{$<20 y$} & \multicolumn{2}{|c|}{$20-30 y$} & \multicolumn{2}{|c|}{$30-40 y$} & \multicolumn{2}{|c|}{$40-50 y$} & \multicolumn{2}{|c|}{$50-60$ y } & \multicolumn{2}{|c|}{$>60 y$} & \multicolumn{2}{|c|}{ Total } \\
\hline & $\mathrm{F}$. & M. & $\mathrm{F}$ & M. & $\mathrm{F}$. & M. & $\mathrm{F}$. & M. & $\mathrm{F}$ & M. & $\mathrm{F}$. & M. & & M. \\
\hline Jan & 2 & I & 13 & 3 & 15 & 4 & 13 & 3 & 14 & 2 & 13 & 2 & 70 & 15 \\
\hline Feb & 2 & I & 3 & I & 9 & 2 & 12 & 4 & 7 & 2 & I & I & 34 & II \\
\hline Mar & 3 & 0 & 9 & 10 & 24 & 7 & 21 & 7 & 15 & 3 & 10 & 8 & 82 & 35 \\
\hline Apr & 5 & I & 12 & 3 & II & 6 & 13 & 4 & II & I & 7 & I & 59 & 16 \\
\hline May & 6 & 0 & 10 & 3 & 15 & 10 & 6 & 5 & 7 & 5 & 5 & 4 & 49 & 27 \\
\hline Jun & I & I & 8 & 2 & 10 & 9 & 12 & 4 & 8 & I & 10 & 4 & 49 & 21 \\
\hline Jul & I & 0 & II & 2 & 9 & 8 & 8 & 4 & 7 & 2 & 4 & 2 & 40 & 18 \\
\hline Aug & 3 & 0 & 15 & 4 & 18 & 6 & 17 & 9 & 12 & I & 3 & 4 & 68 & 24 \\
\hline Sep & I & 2 & 5 & 5 & 9 & 7 & 10 & 2 & 9 & 0 & 10 & 3 & 44 & 19 \\
\hline Oct & 2 & I & 14 & 3 & 21 & 13 & 10 & 5 & 7 & 3 & 10 & 2 & 64 & 27 \\
\hline Nov & 3 & 0 & 9 & I & 10 & 5 & 14 & I & II & I & II & I & 58 & 9 \\
\hline Dec & 0 & 0 & 8 & 2 & 14 & 3 & 13 & 4 & 9 & 2 & 13 & I & 57 & 12 \\
\hline Total & 29 & 7 & 117 & 39 & 165 & 80 & 149 & 52 & 117 & 23 & 97 & 33 & 674 & 234 \\
\hline
\end{tabular}

In general all patients in the 4 years were $2.7: 1$ female/male ratio in range and all had chronic neck pain without any secondary underlying diseases, infection and trauma. In all age groups most of them both females and males commonly in 30-50 years of old in range which could be explained by increase the incidence of the daily activity works and breast feeding for females in this age group, our results fit with international ratio of age and sex distribution.
We found that the no. of females patients with chronic neck pain in the study were 2588 and 243 of them had HT in all age groups without underlying pathology in the 4 years (Table 5). While the total no. of males patient with chronic neck pain in our study in 4 years were 955 and those how had HT in all the age groups without any underlying pathology were 63 patients (Table 6). 
Table 5 No. of chronic neck pain female patients with HT

\begin{tabular}{|c|c|c|c|c|c|c|c|c|}
\hline Year & 2015 & & 2016 & & 2017 & & 2018 & \\
\hline $\begin{array}{l}\text { Month/no } \\
\text { patients }\end{array}$ & Female & $\mathrm{HT}$ & Female & $\mathrm{HT}$ & Female & $\mathrm{HT}$ & Female & HT \\
\hline Jan & 68 & 5 & 80 & 3 & 53 & 11 & 70 & 7 \\
\hline Feb & 61 & 6 & 65 & 3 & 37 & 4 & 34 & 8 \\
\hline Mar & 68 & 5 & 64 & 4 & 57 & II & 82 & 16 \\
\hline Apr & 61 & 4 & 60 & 5 & 50 & 6 & 59 & 9 \\
\hline May & 61 & 8 & 34 & 2 & 35 & 5 & 49 & 3 \\
\hline Jun & 60 & 0 & 62 & 5 & 27 & 4 & 49 & 2 \\
\hline Jul & 37 & 5 & 40 & 4 & 59 & 9 & 40 & 0 \\
\hline Aug & 66 & 2 & 49 & 3 & 47 & 5 & 68 & 3 \\
\hline Sep & 75 & 5 & 60 & 4 & 50 & 7 & 44 & 8 \\
\hline Oct & 60 & 7 & 47 & 4 & 40 & 4 & 64 & 3 \\
\hline Nov & 68 & I & 55 & 6 & 31 & 7 & 58 & 3 \\
\hline Dec & 41 & I & 49 & 6 & 37 & 0 & 57 & 10 \\
\hline Total & 726 & 49 & 665 & 49 & 523 & 73 & 674 & 72 \\
\hline
\end{tabular}

$P=0.00000$

Table 6 No. of male patients with chronic neck pain and had HT

\begin{tabular}{|c|c|c|c|c|c|c|c|c|}
\hline Year & 2015 & & 2016 & & 2017 & & 2018 & \\
\hline $\begin{array}{l}\text { Month/no } \\
\text { patients }\end{array}$ & Male & HT & Male & $\mathrm{HT}$ & Male & HT & Male & HT \\
\hline Jan & 18 & 4 & 26 & 0 & 16 & 4 & 15 & I \\
\hline Feb & 19 & I & 17 & 0 & 12 & 3 & II & 0 \\
\hline Mar & 27 & I & 28 & I & 27 & 3 & 35 & 5 \\
\hline Apr & 26 & 0 & 23 & 0 & 20 & I & 16 & I \\
\hline May & 24 & I & 17 & 0 & 9 & 0 & 27 & I \\
\hline Jun & 19 & 1 & 17 & 2 & 22 & 3 & 21 & 2 \\
\hline Jul & 18 & 0 & 28 & 3 & 10 & 0 & 18 & I \\
\hline Aug & 21 & I & 26 & 2 & 19 & 2 & 24 & 2 \\
\hline Sep & 31 & 2 & 26 & 0 & 19 & I & 19 & I \\
\hline Oct & 24 & 1 & 24 & 1 & 17 & 1 & 27 & I \\
\hline Nov & 14 & I & 22 & 3 & 10 & I & 9 & 0 \\
\hline Dec & 11 & 1 & 13 & 3 & 21 & 1 & 12 & 0 \\
\hline Total & 252 & 14 & 267 & 15 & 202 & 20 & 234 & 14 \\
\hline
\end{tabular}

$P=0.00000$

\section{Conclusion}

The published articles that deal with the relation between chronic neck pain and cervical spondylosis and HT are little and not focusing on can considered it is a risk factor of raising blood pressure or not. In healthy individuals, increase blood pressure is associated with diminished acute pain sensitivity. These cardiovascular/pain regulatory system altered in patients with chronic pain; and elevated blood pressure is associated with increased acute and chronic pain responsiveness. If these alterations reflect failure of overlapping systems modulating pain and blood pressure, it was expected that prevalence of clinical hypertension would be increased in the chronic pain population. ${ }^{20}$

\section{References}

1. Chobanian AV, Bakris GL, Back HR, et al. The seventh report of the joint national committee on prevention, detection, evaluation, and treatment of high blood pressure: the JNC 7 report. Institute joint national committee on prevention, detection, evaluation, and treatment of high blood pressure; National high blood pressure education program coordinating committee. JAMA. 2003;289(19):2560-2572. 
2. Kearney PM, Whelton M, Reynolds K, et al. Global burden of hypertension: analysis of worldwide data. Lancet. 2005;365(9455):217223.

3. MacMahon S, Peto R, Cutler J, et al. Blood pressure, stroke, and coronary heart disease. Part 1, prolonged differences in blood pressure: prospective observational studies corrected for the regression dilution bias. Lancet. 1990;335(8692):765-774.

4. NCD Risk Factor Collaboration. Worldwide trends in blood pressure from 1975 to 2015: a pooled analysis of 1479 population.

5. Chow CK, Teo KK, Rangarajan $\mathrm{S}$, et al. Investigators. Prevalence, awareness, treatment, and control of hypertension in rural and urban communities in high-, middle-, and low-income countries. JAMA. 2013;310(9):959-968.

6. Feng $\mathrm{J}$ He, Graham A. Blood pressure is the most important cause of death and disability in the world. European Heart Journal Supplements. 2007;9:B23-B28.

7. Williams B, Mancia G, Spiering W, et al. 2018 ESC/ESH Guidelines for the management of arterial hypertension. Eur Heart J. 2018;39(33):30213104.

8. Jeffrey Mullin, Daniel Shedid, Edward Benzel. 2011 Overview of Cervical Spondylosis Pathophysiology and Biomechanics. World Spinal Column Journal. 2011;2(3): 89-97.

9. Boden SD, McCowin PR, Davis DO, et al. Abnormal magnetic-resonance scans of the cervical spine in asymptomatic subjects. A prospective investigation. J Bone Joint Surg Am. 1990;72(8):1178-1184.

10. Lehto IJ, Tertti MO, Komu ME, et al. Age-related MRI changes a $0.1 \mathrm{~T}$ in cervical discs in asymptomatic subjects. Neuroradiology. 1994;36(1):49-53.
11. Bogduk N. Distinguishing primary headache disorders from cervicogenic head- ache: clinical and therapeutic implications. Headache Current. $2005 ; 2: 27-36$

12. Bogduk N, Govind J. Cervicogenic headache: an assessment of the evidence on clinical diagnosis, invasive tests, and treatment. Lancet Neurol. 2009;8(10):959-968.

13. Binder AI. Cervical spondylosis and neck pain. BMJ 2007;334(7592):527-531.

14. Morishita Y, Falakassa J, Naito M, et al. The Kinematic Relationships of the Upper Cervical Spine. Spine. 2009;34(24):2642-2645.

15. Whysall ZJ, Haslam RA, Haslam C. Processes, barriers, and outcomes described by ergonomics consultants in preventing work-related musculoskeletal disorders. Appl Ergon. 2004;35(4):343-351.

16. Leenen FH, Dumais J, McInnis NH, et al. Results of the Ontario survey on the prevalence and control of hypertension. CMAJ. 2008;178(11):14411449.

17. Marcella Saccò, Michele Meschi, Giuseppe Regolisti, et al. The Relationship between Blood Pressure and Pain. The Journal of Clinical Hypertension. 2018;5(5):600-606.

18. News \& Perspective Drugs \& Diseases CME \& Education Academy Consult Video New, ASCOT and Other Study Results Show Some Surprising "Causes" of Hypertension: Chronic Pain Associated With Increased Prevalence of Hypertension, 2018.

19. Bruehl S, Chung OY, Jirjis JN, et al. Prevalence of clinical hypertension in patients with chronic pain compared to nonpain general medical patients. Clin J Pain. 2005;21(2):147-153.

20. Peng B, Pang X, Li D, et al. Cervical Spondylosis and Hypertension A Clinical Study of 2 Cases. Medicine (Baltimore). 2015;94(10):e618. 